\title{
Understanding permaculturist motivations among residents of the "PermaKulturRaum" in Goettingen, Germany: a qualitative analysis
}

\author{
Heinrich Petri $^{1}$ (D) Heiko Faust ${ }^{1,2}$
}

Received: 13 May 2020 / Accepted: 23 October 2020 / Published online: 10 December 2020

(c) The Author(s) 2020, corrected publication 2021

\begin{abstract}
By using an inductive qualitative approach, investigating the micro scale, that is, the individual level, we conducted a case study on the PermaKulturRaum in Goettingen, Germany - an experimental space for students to explore alternative lifedesigns. On the supposition that only a radical transition can achieve sustainability on a global scale, we identified permaculture as an appropriate method to achieve this. However, permaculture is not widely spread and largely ignored by scientific research. We started a first attempt to understand the underlying motivations of permaculturists. Using behavioral studies as our theoretical framework, we found out that behavioral determinants, like biospheric values, green-identity, and the intention to act green were extraordinarily high and that the core of their pro-environmental behavior is most likely their strong intrinsic motivation. Regarding the PermaKulturRaum, we could formulate following theses: (1) a comprehensive implementation of permacultural aspects requires an urge for an alternative lifedesign, (2) a radical lifedesign attracts primarily like-minded people, which creates isolated spaces, (3) early childhood experiences or single key moments are important to trigger a pro-environmental interest.
\end{abstract}

Keywords Behavioral geography · Permaculture · Pro-environmental behavior · Sustainable lifestyle $\cdot$ Sustainability $\cdot$ Sustainability transition

Electronic supplementary material The online version of this article (https://doi.org/10.1007/s4354 5-020-00024-2) contains supplementary material, which is available to authorized users.

Heinrich Petri

heinrich.petri@uni-goettingen.de

1 Division of Human Geography, University of Goettingen, Goettingen, Germany

2 Centre of Biodiversity and Sustainable Land Use, University of Goettingen, Goettingen, Germany 


\section{Introduction}

On the supposition that humanity is at a crossroads because of unsustainable human behavior on a global scale, this study raises the following question: What can be done to achieve sustainability? Our answer is: a radical societal transition, done with the help of permacultural principles. Despite a catchy philosophy and practice-oriented principles, permaculture is not widely spread and largely ignored by scientific research and policymakers (Ferguson and Lovell 2014). We assume that permaculturist behavior is too far away from a typical conventional behavior, and therefore its adoption stagnates at a low level. Nonetheless, by better understanding the permacultural way of living, we could gain useful insights about society in general and contribute to a sustainability transition.

To illuminate our assumption, we will identify the motivations that lie behind permaculturist behavior of residents of the PermaKulturRaum (PKR) in Goettingen, Germany. Additionally, we will put their behavior patterns in relation to "ordinary" behavior patterns. To do so, we conducted a qualitative study-a participative field research and semi-structured interviews. The PKR is an experimental space for students to explore alternative lifestyles. Actually, lifestyle is not the appropriate term to describe permacultural behavior (Centemeri 2018). The word lifestyle would suggest that this certain type of behavior is merely a fashion, something that might appear and disappear with the next trend. Therefore, we suggest the term "lifedesign" to pronounce the concept's durability and its profound impact on its proponents.

The PKR is a limited space in which permacultural phenomena take place, it does not represent the German permaculture movement. However, case-specific theses will be formed. These theses can then serve as gate opener for further broader studies.

First, it is important to discuss permaculture's role within the transition research to assess its possible contributions to an actual transition. Next, we outline what permaculture is and particularly our concept of it, followed by a presentation of the PermaKulturRaum. We used behavioral studies, with an emphasis on environmental psychology studies as our theoretical framework. Prominent theories come from this field of research and they are useful to evaluate permacultural behavior as a whole and its underlying motivations. These studies further help to differentiate permacultural behavior from other so-called pro-environmental and ordinary behavior patterns. After explaining our methodology, we present the results of our study and finally discuss them to form case-specific theses.

\section{Transition narratives and permaculture's role}

\section{Transition narratives}

If one wants to see what problems the human race is facing, one can take a look at the 17 sustainable development goals of the United Nations (United Nations 
2019). The UN targets poverty and hunger, inequalities regarding education and gender, environmental problems like a decreasing biodiversity and pollution of different kinds and increasing excessive consumerism-to name just a few. These problems have been well known for decades now. Solving them is still a Herculean task. However, the global community-in the form of intergovernmental politics and transnational institutions-has failed in finding and implementing working answers for a sustainable future yet (Howes et al. 2017). This has led to a growing discontent with national and international politics among many people. This becomes particularly apparent with the current youth movement "Fridays for future", that demonstrates for a more effective environmental policy. The growing discontent, then, raises the question of how a sustainability transition can be achieved. Sustainability transition refers to "large-scale societal changes, deemed necessary to solve grand societal challenges" (Loorbach et al. 2017, p. 600), and as the UN development goals illustrate, the necessity of large-scale societal changes are undisputable.

There are many transition approaches that can be identified. Loorbach et al. (2017) bundle them in three dominant and prominent narratives: (1) the socio-technical, (2) the socio-institutional, and the (3) socio-ecological approach. The sociotechnical approach might be better known as green economy (Luederitz et al. 2017). In a nutshell, the first two narratives follow the sustainability strategies of efficiency and consistency. While efficiency postulates a transition through technological advancement, consistency proponents try to establish closed production cycles. The socio-institutional approach has a stronger emphasis on agency and governance (Allievi et al. 2015; Loorbach et al. 2017). With the socio-ecological approach, the focus of study switches more directly to the bond between (natural) ecological transitions and the societal context. The goal is to protect and strengthen existing socioecological systems through governance (Loorbach et al. 2017).

These narratives have a strong emphasis on top-down governance (Wittmayer et al. 2014) and the goal to optimize existing systems (Beling et al. 2018)- that evidently failed to achieve a sustainability transition (Allievi et al. 2015). Bottom-up processes and grassroot movements play a minor part. The individual responsibility, which is advocated in the study at hand, is almost completely neglected.

Therefore, Luederitz et al. (2017) introduce an additional narrative: ecotopian solutions. Such solutions can be associated with the socio-ecological approach, but they are more critical of dominant systems-like the economic, social, cultural, and the somewhat more abstract value system. Utopian solutions create own spaces outside the conventional, state-led governance. Advocates stress the importance of individual responsibility and communal lifedesign. It is an explicit aim to create individual, experimental, and disconnected solution approaches that, ultimately, influence conventional practices (Luederitz et al. 2017). With these characteristics, the utopian solutions narrative follows the sufficiency strategy known from sustainability sciences that strives to change individual behavior. Sufficiency proponents argue, that the adoption of pro-environmental behavior (PEB) that can be defined as "behavior that harms the environment as little as possible, or even benefits the environment" (Steg and Vlek 2009, p. 309), is the only way enable a sustainability transition (Allievi et al. 2015; Heindl and Kanschik 2016). Prime examples for 
utopian solutions are the widely spread transitions towns network and the concept of eco-villages (Feola and Jaworska 2019).

\section{Permaculture's role within transition research}

Even though critics often characterize such solutions as defiant, and escapist, the challenges the global community faces make it quite obvious that only a radical approach will have a chance of success. One utopian solution of particular interest is permaculture (PC). Surprisingly, PC is not only widely ignored by scientific research in general, but also in sustainability transition research (for a comprehensive analysis, why this is the case, see (Ferguson and Lovell 2014)). Permaculture's holistic nature and its inclusiveness of other approaches and philosophies see for example (Aiken 2017; Centemeri 2018; La Puig de Bellacasa 2010; Roux-Rosier et al. 2018) makes it hard to grasp, what permaculture really is and what it stands for. As an example, most techniques permaculturists use did not originate within the permaculture milieu, but are rather adopted from other concepts (Ferguson and Lovell 2014). This confusion is enhanced by the multi-layered definition of permaculture (see Fig. 1). Permaculture can refer to an international movement, to the worldview carried by this movement, to a design system, and to a best practice framework (Ferguson and Lovell 2014). Depending on the layer, the understanding of permaculture and its implementation can vary greatly. Of course, the layers merge and are not to be viewed as completely separate aspects. With this being said, we try to outline what permaculture is, and elucidate our conceptual understanding of it.

The permaculture movement began in the $170 \mathrm{~s}$ with Bill Mollison and David Holmgren. The term itself is a portmanteau of "permanent agriculture", indicating the goal to create "an integrated, evolving system of perennial or self-perpetuating plant and animal species useful to man" (Vitari and David 2017, p. 15). Mollison and Holmgren used PC to "formulate a response to the threat to modern society posed by the environmental crisis" (Holmgren 2016, p. 19). The response was of an ethical, pragmatic, philosophical and technical nature. Basically, it was a new approach to produce food, mainly in the form of organic horticulture, but its meaning soon widened. Nowadays, Holmgren defines permaculture as a

Fig. 1 Multi-layered definition of permaculture (Ferguson and Lovell 2014, p. 255)

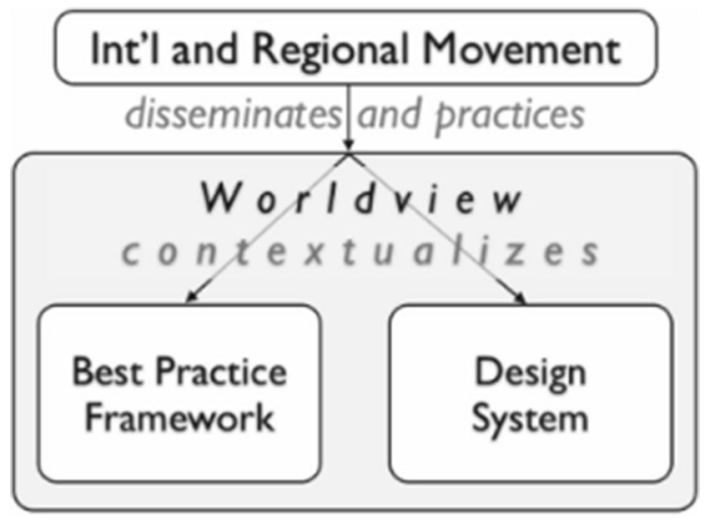


"system thinking and design principles in application" (Holmgren 2016, p. 23). In this sense, permaculture is way more than merely an organic food system. It is rather a design system, which aims to profoundly change our society to create sustainable human settlements. It this sense, permaculture overlaps with ecovillages and transition towns, but its underlying worldview is different. PC proponents expect a technical, economical, ecological, and social collapse, if we do not change our (consumer) behavior. Hence, permaculturists strive not only towards conservation but towards regeneration. Although, self-responsibility is important in PC, the individual is not perceived as a lonely entity on earth. The role of communal life and the interdependence of all forms of life is stressed. The duality between culture and nature is rejected, and humans are perceived as a part of nature. With such a profound premise, it is clear that PC is more than just a lifestyle (Centemeri 2018; Centemeri 2019; Holmgren 2016; La Puig de Bellacasa 2010; McManus 2010).

Permaculture, according to Holmgren, suggests seven domains of action (the permaculture flower) that are to be transformed: (1) land and nature stewardship, (2) building, (3) tools and technology, (4) education and culture, (5) health and spiritual well-being, (6) finances and economy, (7) land tenure and community governance. The permaculture flower illustrates the holistic approach of PC. The base of all permacultural acting are the three ethics: earth care, people care and fair share. While earth care means that humans should sustain a high biodiversity and generally respect the right of existence of all living beings, animals and plants, people care means that we have to respect others and ourselves. Further, we should strengthen immaterial well-being. The ethic of fair share originated on the assumption that nature produces enough for everyone and everything we need. We should only take as much as we need and distribute any surplus. Based on these ethics, Holmgren established 12 design principles which support us in our pro-environmental behavior (Holmgren 2016). To go into further detail would go beyond the scope of this work. However, the principles should not remain unmentioned. They can be seen in Fig. 2 below.

As we conceive permaculture, it is not a blueprint on how to "save the world", it is rather a space, where existing and alternative ideas and concepts can merge. The ethics and the design principles are the conceptual framework in which we can take action for a sustainability transition. The practical implementation of these principles does vary from place to place and project to project. As we already explained in the previous section, not many methods originate directly from the PC milieu, instead other concepts are to be integrated in permacultural behavior. We therefore argue that PC is not only the applying of single PEB patterns, but to design ones everyday practices on the permacultural ethics (La Puig de Bellacasa 2010) and rely on a bundle of pro-environmental methods. Although many of these projects are networked and organized in regional, national, or even international movements, our focus is not on PC as a movement. PC is there to motivate people to take action, to accept self-responsibility and to encourage people to "design" their lives and environment and to ultimately build increasingly self-sufficient human settlements. Hence, we focus on permaculture as a design system and a best practice framework for pro-environmental individuals. 


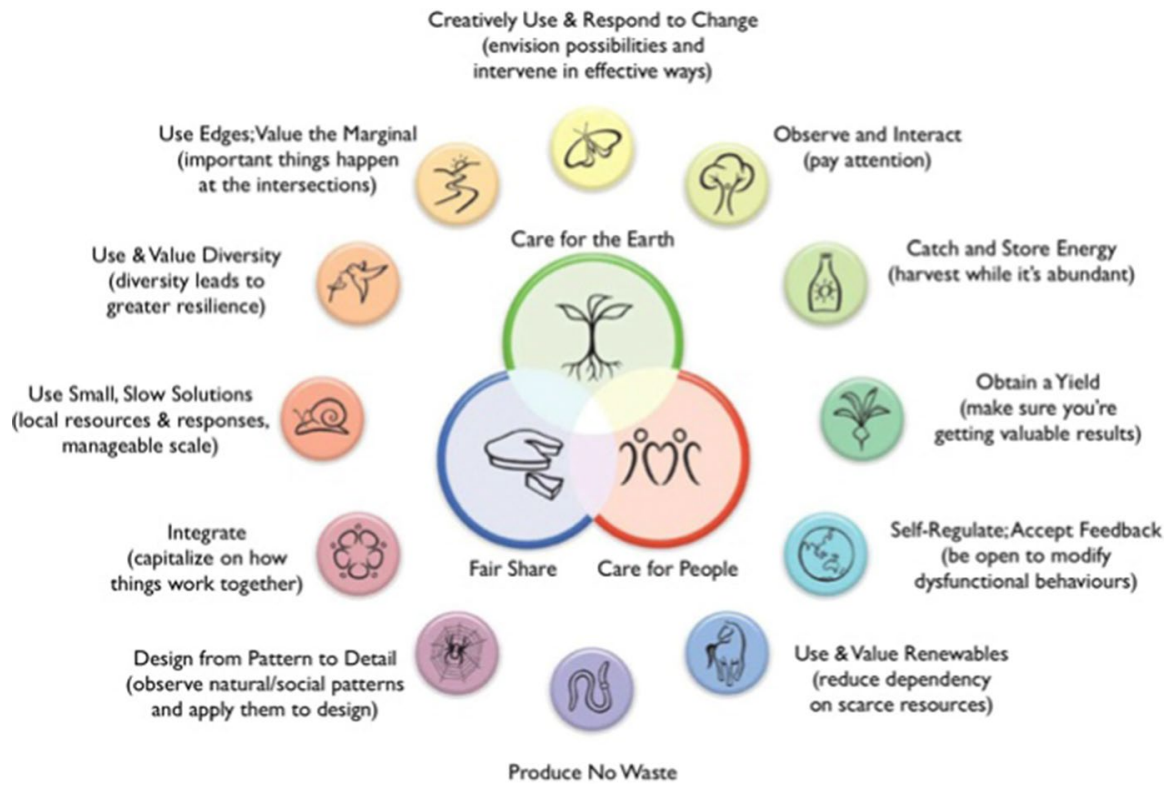

Fig. 2 The 12 design principles with the three ethics as its kernel (permaculture.co.uk 2019)

In summary, permaculture's holistic nature and its inclusiveness makes it hard to grasp its essentials, on the other hand, exactly these characteristics can attract people with different backgrounds. Permaculture stands out, not only in transition research, but also within the utopian solutions narratives. By considering all three strategies of sustainability and it provides a great conceptual framework for people to act, without imposing doctrines or a fixed ideology upon them. Permaculture seems therefore appropriate to solve many problems considered in the sustainable development goals and to give power to people, who feel discontent with current politics. While there are definitely quite a few successful initiatives/demonstration sites (see kommuneniederkaufungen.de; Rhodes 2012), there are, to the knowledge of the authors, no scientific studies that scrutinize possible contributions of permaculture to a sustainability transition, nor do we know any studies that analyze permaculturists motivations. This study at hand is the first try to do so-admittedly on a limited case study. As already mentioned, we do not aim to make any valid statements for the permaculture movement as a whole but focus on the PermaKulturRaum.

\section{Study area: the PermaKulturRaum}

The PermaKulturRaum in Goettingen, Germany was chosen as case study. The PKR as a project started in 2011 on the initiative of students in a cooperation with the faculty of geoscience and geography of the Georg-August university. The goal was to create a space in which students could explore alternative lifedesigns. A former university garden that was unused at that time was chosen as the future experimental 
area. The area comprises about 0.5 ha (see Fig. 3), where about seven students live permanently, many others are involved with the project, without living there. The use of the area is not bound to any conditions on the part of the university, to guarantee maximum freedom to the students. The name "PermaKulturRaum" was chosen to signify the goal to create a space (German: Raum) in which permacultural aspects can happen. Note that the " $\mathrm{K}$ " is capitalized to stress the social importance of the project. Although not a typical example of a permacultural demonstration site, the PKR is filled with permacultural content. At the center of the project area is their community building. It can be considered their social hub. Here they meet to hold plenary sessions in which they discuss important things regarding the project and their living together. They cook and eat together, and they simply are together. They are organized in a grassroots democratic way. The social togetherness is an important pillar in permacultural ethics (people care!).

While the social components are very central to the participants, the agricultural ones are not neglected. They have a vegetable garden that they use to experiment with many permacultural methods and try to produce their own food. They only use organic fertilizer and regularly mulch the garden's soil, on which they cultivate many different (seasonal) plant species. A soon-to-be forest garden is about to produce its first significant yield. All over the place they established perennials. However, their food production is not sufficient to feed them throughout the year. Sometimes they have to buy groceries (strictly only organic), but most of their food is obtained by dumpster diving. Dumpster diving is an unconventional way to practice the fair share approach of PC, since a surplus of perfectly edible food products from supermarkets are collected, that otherwise would have been thrown away. In 2016

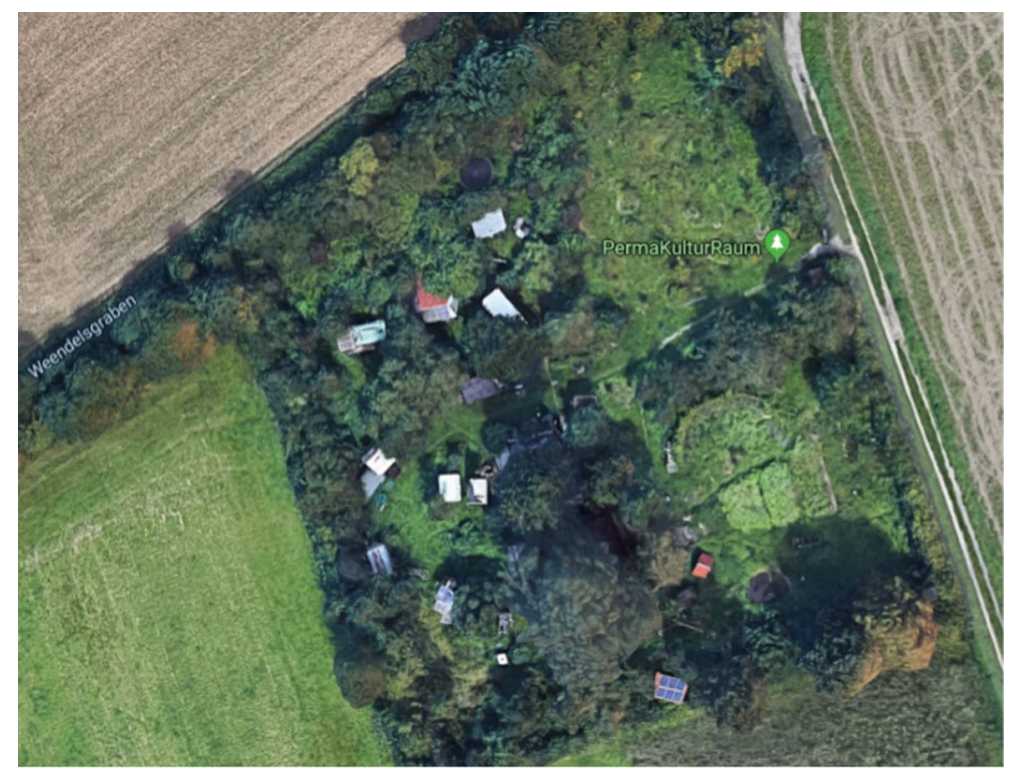

Fig. 3 The PermaKulturRaum area in Goettingen, Germany (google.maps) 
they drafted their first real permaculture design with the help of an experienced permaculturist. According to PC's low energy concept, they heat with wood (residues), which they get from their own trees, or from friends, working in the wood industry. With the help of a university grant, they bought a solar power plant for power generation. They collect rainwater for irrigation and showering. Also, they use dry toilets to save water, and by composting the excrements, they produce their own manure for their shrubberies. In the summer 2020 the work on an earthen cellar started.

\section{Theoretical framework: behavioral studies}

Behavioral studies exist in numerous research fields, like sociology, transition research or behavioral geography. But the origin of the most applied (environmental) behavior theories lies in behavioral and environmental psychology. One of the most used theories to explain behavior is the theory of planned behavior (TPB) by Ajzen, which is an extension of the theory of reasoned action (TRA) by Fischbein and Ajzen. The TPB attributes intentions, which can be defined as "self-instructions to perform particular behaviors" (Webb and Sheeran 2006, p. 249), a key role in the prediction of behavior. Intention, in turn, is predictable by (1) attitudes toward performing the behavior (e.g. X is good/bad), (2) the subjective norm associated with the behavior (e.g. my friends think I should/should not do X) and (3) the concept of perceived behavioral control (e.g. for me it is easy/difficult to do X). The theory also assumed that perceived behavioral control could be used to directly predict behavior, if the perceived and actual control are congruent (Montano and Kasprzyk 2008; Webb and Sheeran 2006), but it also means that if a person perceives a lack of control, he/she might appalled by a certain behavior (Webb and Sheeran 2006).

But of course, there are further determinants for behavior. For example, values are often perceived as an important factor for behavior prediction (Karp 1996; Steg et al. 2014). Values can be described as "desirable goals, varying in importance, that serve as guiding principles in people's lives"' (Steg et al. 2014, p. 107). It is believed that values influence beliefs, norms, attitudes, intention and hence behavior. Schwartz's value theory is one example of an attempt to grasp the importance of values on behavior. Schwartz identified ten motivational types of values (e.g. power, benevolence or tradition) that can predict behavior, if these values are directed to a specific behavior (Groot and Thøgersen 2019; Gutierrez Karp 1996). Four important values for PEB can be differentiated: altruistic, biospheric, egoistic and hedonic. The first two can be described as self-transcendent, the latter two as self-enhancement values. s reflect a concern for nature and the environment for its own sake, while altruistic values represent concern for other humans. Egoistic values reflect costs and benefits affecting individual resources, like money, while hedonic values are concerned with improving one's feelings and reducing effort (Groot and Thøgersen 2019; Steg et al. 2014). Biospheric values can result in a green, that is a pro-environmental self-identity (van der Werff et al. 2014). If a person considers himself/herself as pro-environmental, the chances are higher that he/her will behave pro-environmentally (van der Werff et al. 2013; Whitmarsh and O'Neill 2010). A green self-identity can be enhanced, 
when a person is supported by a minority group. Support by a majority proved to lessen the effects of self-identity on behavior, because it creates a feeling of self-completeness, according to the self-completion theory. Further, a PEB can be lessened, when a majority is anti-environmental (Brick et al. 2017; Lalot et al. 2019).

Another stream of research tries to find out, whether intrinsic or extrinsic motivation is the cause of behavior. Gneezy et al. (2011) for example examined the importance and effectiveness of external incentives to induce a certain behavior (Gneezy et al. 2011). Steg et al. have a research emphasis on finding methods to encourage people in behaving pro-environmentally (Steg et al. 2014; Steg and Vlek 2009; van der Werff et al. 2014). Webb/Sheeran (2006) could show that changing one's intentions can engender behavior changes (Webb and Sheeran 2006). On the other hand, there are several researchers investigating the importance of intrinsic motivation for PEB. It can be observed that some people will behave pro-environmentally, even if there are no external motivations to do so, or even if there are barriers (e.g. higher costs to buy organic food). The motivation comes from within the individual. The source of this intrinsic motivation can either be enjoyment, meaning that a certain behavior brings joy to the person, or it can be obligation, meaning that the person feels obligated to behave in a certain way (Clark et al. 2003; Tabernero and Hernández 2011; van der Werff et al. 2013). Cerasoli/Nicklin (2014) found out that a combination of intrinsic motivation and extrinsic incentives proves to be best considered simultaneously (Cerasoli et al. 2014).

Despite a growing awareness of environmental problems and increases in proenvironmental values, there still is a lack between the values or intention and PEB. This is the so-called intention-behavior-gap (IBG). Even if a person knows, he/she is behaving unsustainable, there is a high chance that he/she will not change this behavior. There can be found numerous reasons for this IBG. There are (1) demographic factors, like gender and education, (2) external factors, like an insufficient infrastructure, (3) economic factors, for example costs of organic food, (4) social and cultural factors, as already mentioned, the social environment can directly influence our behavior, and lastly (5) internal factors, meaning that it is possible that a person simply does (not) have the motivation to act pro-environmentally (Echegaray and Hansstein 2017; Geng et al. 2017; Kennedy et al. 2009).

Figure 4 summarizes the findings on behavior research and illustrates, how difficult it can be to explain behavior and its determinants. Because of the complexity of the subject it is understandable that researches mostly focus on single aspects of PEB, like recycling (Echegaray and Hansstein 2017), travel behavior (Geng et al. 2017) or touristic behavior in hotels (Dolnicar et al. 2017). But there is a lack of scientific knowledge about the drivers for more profound PEB patterns, like we can see in the PC principles. Compared to a "normal" life for most people from the global north, permaculturists' lives can be quite different. The most obvious differences might be their consumption patterns: eating mostly organic food, producing their own food, buying secondhand clothing, repairing, re- and upcycling broken things instead of buying them new, as well as their connectedness to nature. As advocates of PC, we claim that a comprehensive implementation of permacultural principles lead to a more sustainable lifestyle and thus to a pro-environmental society. 


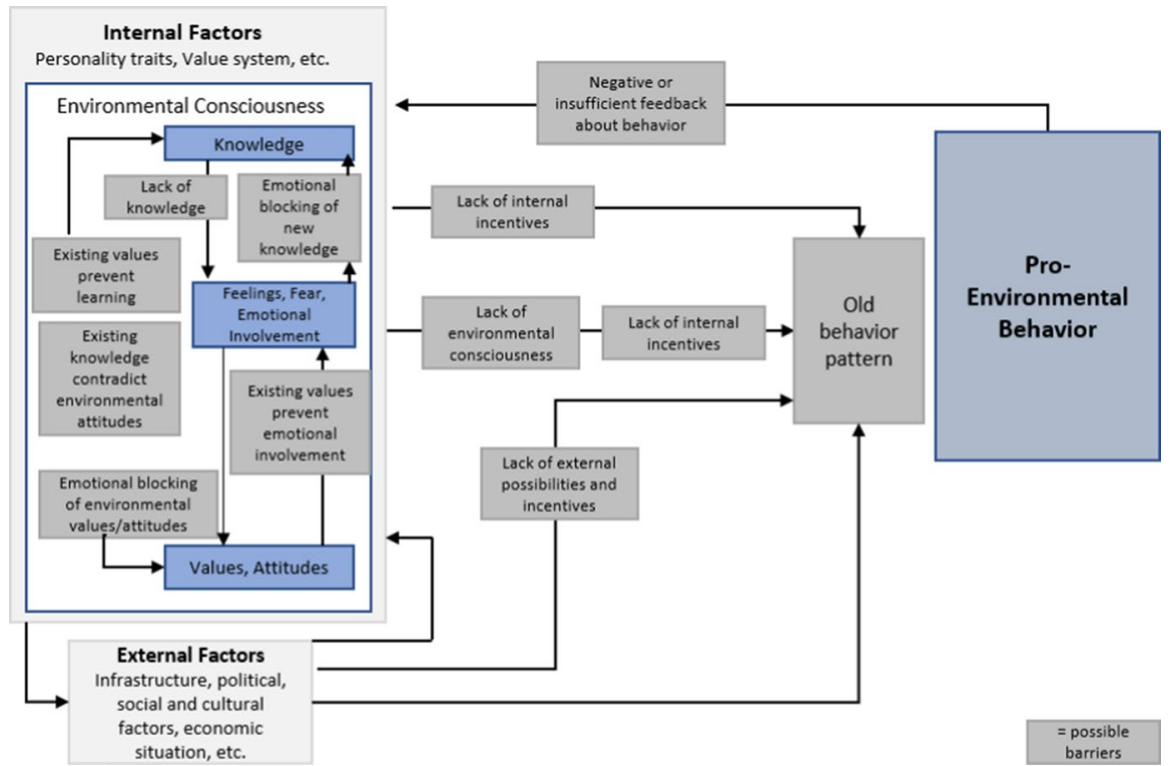

Fig. 4 Model of pro-environmental behavior by Kollmuss and Agyeman (2002), reproduced by the authors

We assume that being a permaculturist implicates many changes compared to a "normal" life. We further argue that, since permacultural principles concern most, if not every aspect of a person's behavior, the IBG is rather small. However, we do not know, what motivations lie behind this drastically different behavior and view previous studies as insufficient to explain the permacultural phenomenon. To our knowledge, this is the first study that examines the motivations for PEB of permaculturists. Since there is no direct data we can rely on for our investigation, we decided on a qualitative approach, following the argumentation of Rosenthal (2018) that this approach is particularly suitable for analyzing unknown social phenomena (Rosenthal 2018). Besides our research questions, we did not formulate any theses beforehand, rather, the analysis gave rise to new theses, which are to be tested in further studies. They are presented at the end of our discussion.

\section{Methodology}

After an initial literature search on permaculture, we noticed a deficiency of peerreviewed studies about permaculture in general and about its implementation in reallife laboratories, respectively. Thus, we could barely rely on existing studies. Even if there is sufficient material on behavioral studies, we do not think, they are adequate to explain permacultural behavior, given its holistic nature. According to Rosenthal (2018) qualitative (social) research has been developed for exploration of hitherto unknown social phenomena, which is clearly the case with PC. Contrary to quantitative research, we did not formulate theses that we wanted to test with our interviews. 
For this kind of research, it is important for the researchers to be as unbiased as possible. We therefore started our research with one question: What motivates the residents of the PermaKulturRaum to engage in a permacultural live model? This open question led to interviews, which, in turn, led to our newly acquired case-specific theses that should be tested in further studies (Rosenthal 2018).

For our research we regularly visited the PermaKulturRaum project to get to know the permaculturists and to better understand their lifedesigns. We also actively participated in their commune. After the initial phase we conducted six semi-standardized interviews to understand their motivations for engaging in permaculture. In July 2019, we conducted six interviews, three of them were each male and female. Of these six interviewees, four were from the PKR project (three males, one female). The initial idea was to interview all seven members of the project, but two left the project at the time of the interviews and one was traveling, and therefore not available. The interviewees were between 24 and 26 years old. While the inhabitants of the PKR project were invariably students of sustainability-related sciences at the university of Goettingen, the two externals were already laborers. To interview only six subjects is nothing compared to any quantitative research, but the sample size cannot be known beforehand in qualitative research and a high number is not always necessary giving the more profound analysis of this approach. The original plan was to focus on solely the PKR project, but since three persons could not be interviewed, we decided to broaden the range of interviewees, which is not common (Mayring 2010) but was perceived as necessary in our case. Through personal contacts we had five more possible interviewees, of which two agreed to be interviewed. A positive side effect was that we could compare permaculturists in their initial phase with two, who have more experience.

We held constant contact with the PKR inhabitants for four months before we conducted the interviews. We were present at a plenum, worked with them together in the garden and on other projects and even accompanied them on their dumpster diving sessions. This participative field research made it easier to understand and to assess their permacultural lifestyles regarding the differences and similarities to a "normal" life, to see not only behavioral aspects, but to get the "whole picture" of their lifedesign. It further helped us to assess their statements made during the interviews (Gatersleben 2019; Rosenthal 2018). There was unfortunately no personal contact prior to the interviews with the two externals. One interview was held over skype and cell phone, for the other we visited the interviewee at her commune, where she lived at that time. Every interview was preceded by an informal conversation. After the actual interview, a casual conversation was maintained for at least half an hour. These measures were important to make sure that the interviewees would not feel like a simple source of knowledge, but that they knew, we had sincere interest in them and in their actions. Therefore, it was important to create an atmosphere that did not feel like an interview, but mostly like an everyday conversation (Lamnek 2010). To enhance this light atmosphere, all personal interviews were conducted in the habitual social environment of the interviewees, that is at the PermaKulturRaum and in case of the external in her commune.

The interviews were semi-standardized, that is, we used key questions (Online Appendix A) for orientation and to prevent the interviews from completely losing 
course. But nonetheless, they were open enough, giving the interviewees the possibility to set their own priorities. The key questions could vary in order, be rephrased or be omitted, if they were already answered or inept (Lamnek 2010; Rosenthal 2018). The function of the first question was always to generate a longer narrative, the interviewees were asked to talk about the way that lead them to their current lifestyle. The interviews were conducted mostly in German, only one was in English. Their durations ranged from 48 to $74 \mathrm{~min}$.

All the interviews were recorded for transcription, after we had the interviewees' consent. The only exception was the skype interview, where recording was not possible due to internet connection problems. We transcribed verbatim, but did not transcribe linguistic stylistics, like pauses, coughs, or anything like that, since we were only interested in the content of what was said and not in the way it was said. To guarantee the interviewees' privacy, we did not use their names in the analysis, instead they are lettered from A to F, and we used the letters to refer to them.

The transcribed texts were analyzed after Mayring's content analysis (Mayring 2010). We first paraphrased the texts, omitting all the non-content supporting text components. In the second step we increased the level of abstraction using generalization. Text parts with similar content were combined and again shortened where appropriate. Unclear text parts were explained by context of the interview itself, or, if necessary, by using context outside of the interview, e.g. observed behavior-this process is called explication. We then subdivided individual text parts of each interview into categories that explain behavioral patterns and motivations (see Online Appendix B). In some cases, subcategorization was appropriate. The categories were created according to Fig. 4. After that we reviewed our summaries and the categorization with the original transcriptions. In a last abstraction we reduced the categories of the individual interviews by bundling them. Mayring calls this procedure "inductive category formation" (Mayring 2010, p. 84). These bundled categories are then to be interpreted in the context of the research question. By following this procedure, we increase the objectivity of the analysis and make it possible for other researcher to compare our results with theirs (Mayring 2010). The last step of our content analysis was a feedback conversation with interviewees, where we talked about our results. This step ensured that we did not misinterpret anything and gave the interviewees the chance for further thoughts and notes.

Given the nature of the cooperation between the university and students, and the purpose of the PKR, it is not surprising that the case study consists of a homogenous group of people regarding their age and educational background. And as such, both, the PKR, and the two additional interviews have only limited validity to represent $\mathrm{PC}$ as a movement. However, several studies mitigate this limitation a little bit. There are studies that suggest a positive correlation between younger age and pro-environmental consumer behavior and pro-environmental beliefs, as well as a positive correlation between higher educational levels and PEB (Gifford and Nilsson 2014; Park et al. 2012; Patel et al. 2017). An unrepresentative survey conducted by Ferguson and Lovell (2015) also points to the high representation of younger, high educated people among permaculturists. Nonetheless, the causation between age and education is still under debate and the cited studies should not create the impression of a representative claim in this study at hand. 


\section{Results}

In this section we present our results of the interviews and the participative field research. We created 22 interview-specific categories altogether that were then bundled into six main categories. Some interview-specific categories could contribute to several main categories. In this section we first introduce the interviewees, then present and explain the main categories. The results are summarized in Table 1.

\section{Presentation of the interviewees}

The first interview was conducted with A. A is male, 25 years old and he studies Sustainable International Agriculture. He has lived at the PermaKulturRaum since October 2018. B is also male, 25 years old and joined the project at the same time. $\mathrm{He}$ is a master student in forestry. $\mathrm{C}$ was the only female interviewed from the PKR, She, too, is 25 years old, and a master student in sustainability sciences. Only a week after the interview she left the PKR after two years to live in a newly founded commune in the Black Forest in Southwest Germany. D is male, 26 years old, he studies biodiversity and is the longest member of the PKR, living there since 2013. E was the first interviewee from outside the PKR. She is female, 26 years old, and has much expertise in agriculture and horticulture. At the time of the interview she was traveling through Germany, Switzerland, and Austria to visit and work on different small farms and business to learn more about alternative food production systems. It was the only not face-to-face interview. F is female, 24 years old, and was also not from the PKR. At the time of the case study she lived in a commune in Niederkaufungen, Germany. The commune already exists for 30 years. It is centrally located in the village. The commune consists of 55 adults and 21 children (September 2019). There are several commune-intern businesses, like a kindergarten, day care for dementia patients, horticulture, seed production and a farm shop. They further have a communal economy and open-mindfulness and no hierarchies are key factors in their policy.

\section{C1: the importance of (early) socio-cultural influences and experiences on ecological interests}

Three of the six interviewees (A, B, and F) were strongly influenced by their social environment regarding their pro-environmental awareness at a young age (childhood). For example, to see his father, a conventional farmer, working on his field, sowing, and harvesting, relying on the weather and so on, raised A's early awareness for human dependence on nature. He had an early sensitization about the difficulty of food production, that later gave him a less romantic, more realistic view on permacultural live models. Another important influence were his childhood friends, who gave him another perspective on nature. With them, he often dwelled in natural landscapes, they played being Indians and they taught him how to fish. He recalls that during this time he aspired for the first time to be an environmentalist. He seemed also to be strongly 
Table 1 The main categories (left column) with interview examples (right column)

Main categories (interview-specific categories in Interview examples brackets)

C1: The importance of (early) socio- cultural influences and experiences on ecological interests (c1, c4, c9, c14, c20)

C2: Past behavior mediates future behavior (c2, c7, c12, c16)

C3: Self-responsibility is considered to be very important (c3, c7, c18, c19)

C4: The relation to the "system" (c5, c10, c15, c21)

C5: PermaKulturRaum as a place of learning and personal development (c6, c11, c14)

C6: The role of (inexplicable) intrinsic motivation for PEB (c5, c8, c10, c18, c19, c22)
A: father's profession, childhood friends, school

B: Grandparents, parents, friends

C: social environment during childhood had no understanding for her pursuit for an alternative living, her work at a recycling center

D: remembers no (positive) influence from family and friends until he went to university

E: remembers no influence from friends and family at all, she could not explain her interests in ecology

F: parents' lifestyle

A: choice of field of study in his bachelor and masters, and his plans to create grassroot democratic spaces to spread pro-environmental ideas

$\mathrm{B}$ : the wish to continue his permacultural lifestyle in the future, and his plans to work as a Treeclimber in the near future

C: her choice to leave the PKR and join another, bigger and better organized community

D: future plans to live in a similar community like the PKR but better organized

E: her ongoing traveling and the idea to create an own community

F: her apprenticeship at the German Permaculture Academy and the idea to create an own community

A: the perception that everything is political, and drive to act permacultural, independent of the outcome

E: Does no think, she can change someone's mind, therefore she is concentrating on her behavior

$\mathrm{F}$ : is the only one who is politically active

$\mathrm{B}$ : his rejection towards living in an urban environment, his indifference towards what many people find desirable, like wi-fi, tap water, electricity, the importance to live close to nature/with nature

$\mathrm{C}$ : her choice to join a larger community, which can be considered an eco-village and the early wish to live differently than her family

D: his dissatisfaction with politics and "the system"

F: her plans to create an own community with permacultural aspects, the perceived absurdity to graduate university and having a regular job, rejects to live in a large city

Statements made by all PKR members

B: Continuation of permacultural life, despite lack of understanding of his family and some friends $\mathrm{C}$ : leaving her old life, to explore new life models F: leaving Berlin, where she felt like an outsider 
influenced by his education at a Waldorf school. Here, he learned alternative ways of living, his school raised his awareness of globalization and problems associated with it. It was also in this school environment, where he first learned about organic agriculture, and a husband of one of his teachers gave him the idea to study landscape ecology and nature conservation.

B was also early influenced by his social environment. His parents frequently took him hiking, kayaking, climbing, and skiing. These trips were often exhausting but they let him experience nature in a particular intense way. Another huge influence were his grandparents. During his childhood, he spent every summer vacations on their selfbuilt vacation house. The building was located in the mountains, with only a few neighbors around. Although they had electricity and tap water, B tells, how much work they had to do, like wood chopping and maintenance work. His grandfather taught him how to use tools and how to repair his stuff. He also taught B to respect and to live in harmony with nature.

The last interviewee, who stressed the influence of early childhood experiences is F. She told us, how she was raised by her parents with permacultural values (of course, without knowing permaculture at that time). She grew up on the country site, where her parents had a vegetable garden for their own food production. The building was renovated by her parents and equipped with a solar plant. Especially her father, a carpenter, taught her how to maintain and repair her stuff. She talked about, how it was normal for her to scrutinize existing systems and to be a freethinker.

Especially A and F stressed that after their childhood, they did not need any further support from other people to engage in PEB. On the contrary, D had no early influences regarding his current state of mind, and he does not remember that he had much interest in ecological issues. But he told us about his left-wing orientated political views and his dissatisfaction with the "system". However, only a friend at his university triggered his interest in permaculture, and sustainability in general. She introduced D to permaculture and the PKR, where his alternative and ecological worldview was shaped. C had always to urge to live differently, without being supported in any way by her environment. She always felt misunderstood by her parents. Attempts to live a little bit differently where not supported. For example, she wanted to join a scouts' club, but her parents would not take her, because of the distance. Her diffuse endeavor for "doing things differently" became more concrete, after working at a recycling center, where she realized, how ecological harmful humans live and how much waste is produced.

Maybe surprising, E was the only interviewee, who did not recall any influence from her social environment or any experience that might have triggered her current interest in nature conservation. After high school graduation, she first studied economic mathematics, but then changed the subject to landscape ecology. However, she could not describe, where this sudden interest came from.

\section{C2: past behavior mediates future behavior}

An interesting insight that came from the interviews was that all interviewees stated that they definitely pursue a continuation of their current lifedesigns, and that, once their pro-environmental mindset was triggered, it led to further PEB patterns. 
A, who described his pro-environmental development as a straightforward path, continued and expanded his PEB. His early childhood experiences and his educational background made him study landscape ecology. During his bachelor studies, he chose to do a semester abroad in Tanzania, where learned about permaculture. After his graduation, he traveled to South America to learn about local cultivation methods and there, he deepened his connectedness to nature. When he began his master studies in Goettingen (sustainable international agriculture), he actively looked for a place like the PKR. Also, A' future plans suggest his motivation maintain his PEB. He wishes to actively contribute to a sustainable world, by creating spaces, in which people can learn new approaches to nature and food production.

B's past behavior also led to further PEB. For example, when he first went to university, he could not live like he used to do-close to nature, in silence, and with deep communication with his social environment. This made him so unhappy that he actively went looking for alternatives, until he found one: people with whom he moved in together and with whom he organized workshops and conferences. His future plans tend to the same direction. B wishes to continue to live like he does now in the PKR. His current dream job is also closely related to his nature connectedness: Treeclimber (arborist). D and F, both, enjoy the permacultural community living very much, and both do plan to create an own community after they leave their current ones. C, was already on her way out of the PKR, when we interviewed her. She was about to join a Southwestern Germany community in the Black Forest. The community is called "Akademie für angewandtes gutes Leben" (academy for applied good life). The community is well organized and is grassroot democratic structured. On 70 ha farmland that they own, they produce much of their food supply. The academy also serves as a demonstration site of alternative living.

\section{C3: self-responsibility is considered to be very important}

Interviewees $\mathrm{A}, \mathrm{E}$ and $\mathrm{F}$ were the ones, who explicitly pronounce the importance of self-responsibility. A told us, how he thinks that there are many wrong developments right now, and he sees it as his meaning of life to counteract those. He feels happy to do so, and it does not matter to him, if he actually changes something, as long as it feels right to him. E said that individual responsibility and self-control are central to her, which is why she does not try to change someone else's behavior. F stresses the importance to learn only practical things that she can use for her permacultural lifedesign. It is further very important to her to be independent and self-responsible. If see recognizes something that she perceives as wrong, she tries to change it/to do is different. E's motivation for nature conservation is primarily obligation-oriented, which also supports her focus on selfresponsibility. In general, all interviewees showed a dissatisfaction with the existing "system" (see "C4: the relation to the "system""), but instead of complaining or passing the responsibility to others (e.g. politics), they all have decided to accept responsibility and to engage in what we call permacultural lifedesign. 


\section{C4: the relation to the "system"}

In general, it seems only logical that people, who strive after utopian solutions like PC, test alternative lifedesigns. The interviews and the field observation showed interesting motives for this pursuit. D said it most directly: he is dissatisfied with the current "system". He sees many problems in the German society. However, he feels powerless, he does not see any ways for him to change something within the system, which frustrates him. He particularly criticizes the political system and its four-year policy that, in his opinion, can only find short-term solutions for long-lasting problems. He thinks that there is a lack of inclusiveness and a lack in teaching people how to find solutions that can be accepted by everyone-which he considers to be the very basis for a society. D considers the permacultural ethics and other permacultural methods and tools as suitable to establish permanent structures in which people can live together in harmony.

B has similar problems with the system. He stresses the negative impact of urban lifestyles on his health. Busy roads, loud people, concrete everywhere-every time he visits his girlfriend in the city, he starts to feel sick and is sleep deprived after a few days. Only when he is back at the PKR, surrounded by trees and shrubberies he feels happy again. Of course, he uses electricity and the internet, however, he criticizes the consumerism of modern society. He shows dissatisfaction with the economic system that relies on this consumerism, and particularly he rejects the importance of money. In the PKR he does not need much money, which he describes as liberating. His biggest problem seemed to be the social system. During the interview he often emphasized, how important communication is to him, and how he feels that it is lacking in the society. This, in turn, leads to many misunderstandings and hence to conflicts. To live an alternative lifedesign is so important to B that even his parents and friends from outside the PKR could not change his mind. Although they were not opposed to his connection to the PKR, they did not understand, why he would to that. His parents were shocked, when they first saw, where he lives now. Still, he has pursued his way.

$\mathrm{C}$ is an interesting case. She seemed to have had an intrinsic wish to live differently. For a long time, this wish was very diffuse. Her work at a recycling center triggered her pro-environmental interest. But precise plans to live outside the incumbent system only took form, when, after her bachelor graduation, she decided to cut off all her social contacts and move to Hungary. There she learned about an international ecovillage design education program in Switzerland, which she attended. For the first time in her life, she like-minded people and an alternative lifedesign that suited her. After she moved to Goettingen, someone told her about the PKR. She immediately wanted to join and is now moving to another, larger and better organized community.

F's relation to the system is also quite interesting. Although she already grew up rather alternatively, she did not feel the urge to leave the incumbent system for a long time. This changed when she lived in Berlin. The (relatively) normal life she had back then seemed dull to her. Studying to get a degree and then to work in a nine-five job was undesirable to her, and she was annoyed that she had to take an hour trip just to be in a natural landscape. She felt like an outsider in the 
urban environment, where everything and everyone hast to function all the time, and the only thing to do is to consume something. That is why she left Berlin and went on to explore different communities with alternative approaches to human settlements.

\section{C5: the PermaKulturRaum as a place of learning and personal development}

All of the PKR residents told us, how much they appreciate the project's social atmosphere and its experimental character. When A came to Goettingen, e was only looking for a parking lot for his trailer. But when he met and joined the PKR project, he immediately enjoyed the concept and the idea behind the project. A and $\mathrm{C}$ already knew permaculture beforehand, but living here, they could deepen their permacultural understanding and experiment with permacultural methods. B and D had their first encounter with permaculture through the PKR. This project has had a deep impact on D, changing and developing many of his ideas and social concepts. For all of them, but particularly for B and C, the opportunity to live basically in a natural environment feels like luxury to them. All of them consider the social aspects as a particular strength of the PKR. They appreciate the perceived deeper communication and the harmonious living together. After a turbulent year in 2019 with many changes, in 2020, they redesigned several structures and improved their organization. Together they transformed the PKR within a year to a successful demonstration site, with workshops and open days.

$\mathrm{E}$ and $\mathrm{F}$ have made similar experiences. $\mathrm{E}$, for example, lived in the eco-village Tempelhof in Southern Germany, where she learned much about alternative lifedesigns and cultivations methods. She also learned that even a village like Tempelhof with 150 residents is too large for her. F, who already lived in several alternative communities, learned much about social living and the organization of such communities.

\section{C6: the role of (inexplicable) intrinsic motivation for PEB}

Despite identifying several determinants that triggered and supported the interviewees' pro-environmental worldview and behavior, there seems to be something more inherently that enables this kind of behavior. For example, A, B, and F had all early childhood experiences that triggered their pro-environmental mindset However, for years now, such influences are not recognizable. C and D's PEB were triggered by (external) key experiences, but after those, further external influences seemed to be unnecessary. B actively changed his life situations, when he could not live his pursued alternative lifedesign, $\mathrm{C}$ changed her life radically to break out of the incumbent system, and F left Berlin after realizing that an urban lifestyle does not suit her. E said that she had none of such external influences at all. The consequence with which the interviewees are willing to change dissatisfying life situations and to follow desirable lifedesigns indicates distinct intrinsic motivations. 


\section{Discussion}

The goal of this work was to learn more about the motivations of residents of the PKR to engage in permaculture, and in general to better understand the permacultural lifedesign. We consider permaculture as an appropriate way to enable the transition from our current destructive society to a permanent sustainable global community. At the same time, permaculture is an extreme form of pro-environmental behavior that can require a complete redesigning of one's life.

We conducted six semi-standardized interviews, four with members of the PermaKulturRaum in Goettingen and two with externals to draw a comprehensive picture of their motivations and to find similarities and differences compared to a "normal" lifestyle. As already mentioned in "Theoretical framework: behavioral studies", previous studies only examined single determinants that might engender behavior, like values, intentions, intrinsic or extrinsic motivations, self-identity, among others. These studies focus strongly on the prediction and the manipulation of PEB but fail to analyze the determinants of PEB of people, who already have a broad PEB. Nonetheless, these studies are helpful to put our results in a wider context.

The first thing that becomes apparent is the obvious small scale of the intentionbehavior-gap (IBG) among the interviewees. Although, it is still not completely understood why people, who consider themselves as environmentalists do often not behave that way, the gap is quite obvious. Several assumptions can be made about the reasons for the IBG. We mentioned them in "Theoretical framework: behavioral studies", and they are illustrated as barriers in Fig. 4. Sheeran and Webb further divide the IBG into three stages: (1) fail to get started; (2) fail to keep goal pursuit on track and (3) fail to bring goal pursuit to a successful end (Sheeran and Webb 2016). Basically, many people fail in their ambition to act pro-environmentally before their action has even started. Even if the initiation of a PEB was successful, it is usually hard to maintain it. New behaviors are often context-specific and are therefore not adapted outside this specific context. Especially extrinsic induced behavior changes (e.g. reinforcement of alternatives, punishments and so on) are often not long-lasting, since they usually only suppress old behavior patterns, without transforming the underlying behavioral cause (Bouton 2014). So, the question emerges, why is the IBG rather small among the interviewed permaculturists?

\section{Biospheric values}

We begin our examination with the determinant "values". Values can be considered as the foundation of every behavior, since they influence our self-identity, norms, intention that lastly leads to behavior. Values are rather abstract constructs and relatively stable principles and therefore not easy to change. But only if values are related to environmental issues, a person might intentionally behave pro-environmentally, but even then, a PEB is not guaranteed. This type of values is called "biospheric values" (Groot and Thøgersen 2019, p. 172). Biospheric values are directly linked to concerns about the quality of nature and the environment, thus they are the most important values considering PEB patterns. To a lesser extent altruistic 
values, the concern with the welfare of other human beings, can also lead to PEB. Of course, personal values can contradict each other, for example, the wish to protect the environment can be outwitted by egoistic or hedonic values, such as the wish to save money or to be highly mobile and therefore using the car.

The interviews and the field observation revealed comprehensive biospheric values. The way they interacted with their environment and the way they talked about nature signified this. All of the interviewees proclaimed their intention to undertake something for nature conservation. During our field observation we could witness that they put their values into action, for example by dumpster diving, buying mostly organic food or living with low energy consumption. Furthermore, F was the only one, who professed no altruistic values, whereas all the other wanted to preserve nature to make a future possible for following generations. The fact that most people of the Western world have biospheric values but still lack the practical implementation of these, shows that these values vary in significance, and that biospheric values often clash with other values (like hedonic ones). Among the interviewed permaculturists, biospheric values were perceived as the dominant value complex.

\section{Green self-identity}

If biospheric values are strong enough, they can shape our (green) self-identity (van der Werff et al. 2014). Several studies have examined the relevance of selfidentity and PEB, so far. The relevance, albeit proven, can vary much. Brick et al. for example found out that people might behave against their own biospheric values, if their social surrounding is anti-environmentalist, which the authors call "brown to keep down". By contrast, people will be encouraged in PEB, if their surrounding supports this behavior, which the authors call "green to be seen" (Brick et al. 2017). This observance can be further elaborated by the studies of Lalot et al., who analyzed the role of minority-majority-groups on self-identity and behavior. If people feel that they are doing worse than a descriptive majority, they might increase their effort, while finding out that they are doing better than their ingroup's average might lead to a reduction of their effort. Furthermore, being a member of a supportive social minority can enhance the efforts to behave pro-environmentally. If the minority group welcomes past behavior patterns, the person might be motivated to continue these patterns, whereas the person may be willing to change past behavior patterns, if they are not supported by the minority group (Lalot et al. 2018, 2019). Although, the results were not totally convincing because of different outcomes in the studies, they can be helpful to understand our own results. Utopian solutions have not reached the mainstream so far, hence permacultural groups are still a social minority, with a higher ingroup identification. The PermaKulturRaum illustrated this minority support. Every interviewed member stated that they enjoyed the influence of the other members, they inspired each other and were motivated to increase their efforts. For example, B said that he goes more frequently dumpster diving than he used to do, C learned to ask others for help, when she needs something, and D learned much about permaculture and social living. F said that she could not implement her biospheric values in Berlin, where the social majority did not live like she 
would to. Only after leaving Berlin and visiting like-minded communities, she realized that she was not alone. Especially among PKR members it was obvious that they see the project as a refuge to live with like-minded people. The ingroup identification was very high. They all stressed the importance of their social interaction and their living together.

\section{Intention}

Biospheric values and a green self-identity should influence the attitudes of a person, like considering organic food as better than conventional or considering extraordinary consumption as bad. These attitudes should then form the intention to act proenvironmentally which, according to the TPB, leads to a PEB. But Webb/Sheeran found out that even if intentions get manipulated, impact on behavior is only smallto-medium (Webb and Sheeran 2006), further elucidating the IBG. Several possible explanations can be gathered. The TPB postulates that a person must perceive they have control over a certain behavior, which is determined by control beliefs concerning the presence or absence of barriers to behavioral performance (Montano and Kasprzyk 2008). But in the case of the permaculturists, perceived control did not seem to really matter. They all stated that their actual influence on the world did not really matter to them, or as A put it: "Even if nothing would change, I still live according to my principles. Even if it is just a tiny thing, if I perceive something as good, I want to implement it in my life." This point of view seems to be remarkable in peoples' mindsets. None of the barriers included in Fig. 4 seemed to matter in the case of the permaculturists. For example, they all have a profound knowledge about environmental issues, and they are all interested to broaden their stock of knowledge. In three cases $(\mathrm{B}, \mathrm{C}$ and $\mathrm{F})$ the lack of external factors, like a proper infrastructure or external possibilities had only a temporarily effect. B, unhappy with the life in an urban environment with only superficial social contacts, left his shared apartment and joined projects that supported his way of living. $\mathrm{C}$ stated that she was looking for like-minded people after she moved out of her parents' house, and F soon realized that Berlin was not the place to live out her preferred lifestyle, so she left. Even their economic situations did not inhibit their PEB patterns if anything they profited from their lifestyles. B for example saves a lot of money by dumpster diving and in general, since none of them strives for economic wealth, money is never really the issue for them.

\section{Intrinsic motivation}

So far, we have seen that many determinants for behavior exist: values, self-identity, intention. Still there is a gap between these determinants and people's actual behavior. But this is not the case with the interviewed permaculturists. Why? It became apparent that the permaculturists' biospheric values and hence their intentions to act pro-environmentally are outstandingly prominent, although there are more than enough other people, who have the same environmental knowledge, a similar background and/or the intention to change something in the world. There seems to be 
something more profound, less tangible than the so far presented determinants. Childhood is deemed to be a particularly formative time. Indeed, there are studies that found a relation between early nature experiences and later pro-environmental behavior (Evans et al. 2018; Thompson et al. 2008), and the relevance of parenting (Grønhøj and Thøgersen 2017). But only three of the six permaculturists could exhibit such a development. In the other three cases, childhood did not seem to have a formative character for their later PEB. Further, as A stated, his two brothers had the same nature experiences as he had, but none of them became really interested in nature conservation.

We therefore argue that the intrinsic motivation that could be found in every interviewee is the core of their PEB. Van der Werff et al. distinguish two types of intrinsic motivations: (1) enjoyment-based intrinsic motivation, which leads to behavior, because it is interesting or enjoyable; and (2) obligation-based intrinsic motivation, where behavior is the result of feeling obliged to perform it. The authors argue that self-identity leads via obligation-based intrinsic motivation to PEB, because PEB is often associated with less pleasure (van der Werff et al. 2013). Indeed, all of the interviewed permaculturists did feel obliged to do something for nature conservation. However, as opposed to van der Werff et al. argumentation, all of the permaculturists did highly enjoy their pro-environmental lifedesigns, thus promoting both, the enjoyment-based and the obligation-based intrinsic motivation. The significance of the intrinsic motivation becomes obvious in different ways. First of all, external incentives/influences were, at all, only needed temporarily - for example as a trigger (C and D), or as early influence. On the contrary, they renounced an allegedly more comfortable life in the city to live out and try out alternative lifedesigns. None of them strived for economic wealth and all were happy with their minimalistic lifestyles. Of course, they were influenced by external barriers, but these were never strong enough to change their actual mindset. Their PEB became or was always habitual. Their pro-environmental development could be described as the "golden thread" in their lives, as A and C called it.

\section{Summary, case-specific theses and new questions}

We used behavioral studies as our framework to identify the motivations of the PKR residents to use permaculture as their lifedesign. Especially behavioral and environmental studies contributed to the extraction of important behavior determinants. However, many behavioral studies only examine these determinants isolated from each other. In this limited case study, we tried to combine several determinants to construct a whole picture of permaculturists' behavior patterns. Beginning with their values, we found out that these were heavenly influenced by early childhood experiences and single triggers. Their biospheric values shaped their green selfidentity which, in turn, strengthened their intentions to act pro-environmentally. We further identified their intrinsic motivation to be at the core of their PEB-no external incentives were needed. We can then use this intrinsic motivation to explain their perceived importance of self-responsibility, which is typical in the permaculture 
movement. The field observation revealed a barely existing IBG, suggesting their comprehensive implementation of permacultural principles.

All of the interviewees signaled an urge to break out of the existing incumbent system. To us, this seemed to be their main motivation to live in permacultural communities, and not just to adopt some sustainable behavior patterns and continue living a rather ordinary life. The dissatisfaction with the existing and the urge to create something alternative seems radical. However, we intentionally chose radical subjects to fully understand necessary determinants of permacultural behavior. We argue that this radical example of permacultural living can help subsequent studies and design more mainstream compatible lifedesigns. To refer to the utopian solutions narrative: only a radical system change accompanied by acceptance of selfresponsibility and a behavior change can lead to a sustainability transition.

Regarding our work with the PermaKulturRaum and the considered literature, we formulate following theses:

1. A comprehensive implementation of permacultural aspects requires an urge for an alternative lifedesign

2. A radical lifedesign attracts primarily like-minded people, which creates isolated spaces

3. Early childhood experiences or single key moments are important to trigger a pro-environmental interest

During our research new questions arose.

- We only interviewed a homogenous group of people, and although some studies suggest that educated adolescent people might be a main target group for sustainable lifedesigns, this statement is highly disputable. Therefore, it be interesting to have a larger case study, with more heterogenous people, considering age, socioeconomic and educational background

- Subsequent studies could follow the question, how the permacultural lifedesign is adaptable for a broader stratum of society

- We identified the intrinsic motivation as the core determinant of permacultural behavior, however, we could not fully grasp this determinant. Subsequent studies could pursue this finding

- Their urge to live in an alternative lifedesign, raises the question, if a permacultural lifedesign is possible, without this urge

Funding Open Access funding enabled and organized by Projekt DEAL.

Data availability Data available on request due to privacy.

Open Access This article is licensed under a Creative Commons Attribution 4.0 International License, which permits use, sharing, adaptation, distribution and reproduction in any medium or format, as long as you give appropriate credit to the original author(s) and the source, provide a link to the Creative Commons licence, and indicate if changes were made. The images or other third party material in this article are included in the article's Creative Commons licence, unless indicated otherwise in a credit line to the 
material. If material is not included in the article's Creative Commons licence and your intended use is not permitted by statutory regulation or exceeds the permitted use, you will need to obtain permission directly from the copyright holder. To view a copy of this licence, visit http://creativecommons.org/licen ses/by/4.0/.

\section{References}

Aiken GT (2017) Permaculture and the social design of nature. Geogr Ann Ser B Hum Geogr 99(2):172191. https://doi.org/10.1080/04353684.2017.1315906

Allievi F, Vinnari M, Luukkanen J (2015) Meat consumption and production-analysis of efficiency, sufficiency and consistency of global trends. J Clean Prod 92:142-151. https://doi.org/10.1016/j.jclep ro.2014.12.075

Beling AE, Vanhulst J, Demaria F, Rabi V, Carballo AE, Pelenc J (2018) Discursive synergies for a 'great transformation' towards sustainability: pragmatic contributions to a necessary dialogue between human development, degrowth, and buen vivir. Ecol Econom 144:304-313. https://doi. org/10.1016/j.ecolecon.2017.08.025

Bouton ME (2014) Why behavior change is difficult to sustain. Prev Med 68:29-36. https://doi. org/10.1016/j.ypmed.2014.06.010

Brick C, Sherman DK, Kim HS (2017) "Green to be seen" and "brown to keep down": visibility moderates the effect of identity on pro-environmental behavior. J Environ Psychol 51:226-238. https://doi. org/10.1016/j.jenvp.2017.04.004

Centemeri L (2018) Commons and the new environmentalism of everyday life. Alternative value practices and multispecies commoning in the permaculture movement. Rassegna Ital Sociol 27722(2):289-314

Centemeri L (2019) Health and the environment in ecological transition: the case of the permaculture movement. In: Bretelle-Establet F, Gaille M, Katouzian-Safadi M (eds) Making sense of health, disease, and the environment in cross-cultural history: the Arabic-Islamic World, China, Europe, and North America (Boston Studies in the Philosophy and History of Science, vol 333. Springer International Publishing, Cham, pp 309-331

Cerasoli CP, Nicklin JM, Ford MT (2014) Intrinsic motivation and extrinsic incentives jointly predict performance: a 40-year meta-analysis. Psychol Bull 140(4):980-1008. https://doi.org/10.1037/ a0035661

Clark CF, Kotchen MJ, Moore MR (2003) Internal and external influences on pro-environmental behavior: participation in a green electricity program. J Environ Psychol 23(3):237-246. https://doi. org/10.1016/S0272-4944(02)00105-6

de Groot J, Thøgersen J (2019) Values and pro-environmental behaviour. In: Steg L, de Groot JIM (eds) Environmental psychology: an introduction (BPS textbooks in psychology). Wiley, Hoboken, pp $167-178$

Dolnicar S, Knezevic Cvelbar L, Grün B (2017) Do pro-environmental appeals trigger pro-environmental behavior in hotel guests? J Travel Res 56(8):988-997. https://doi.org/10.1177/0047287516678089

Echegaray F, Hansstein FV (2017) Assessing the intention-behavior gap in electronic waste recycling: the case of Brazil. J Clean Prod 142:180-190. https://doi.org/10.1016/j.jclepro.2016.05.064

Evans GW, Otto S, Kaiser FG (2018) Childhood origins of young adult environmental behavior. Psychol Sci 29(5):679-687. https://doi.org/10.1177/0956797617741894

Feola G, Jaworska S (2019) One transition, many transitions? A corpus-based study of societal sustainability transition discourses in four civil society's proposals. Sustain Sci 14(6):1643-1656. https:// doi.org/10.1007/s11625-018-0631-9

Ferguson RS, Lovell ST (2015) Grassroots engagement with transition to sustainability: diversity and modes of participation in the international permaculture movement. Ecol Soc. https://doi. org/10.5751/ES-08048-200439

Ferguson RS, Lovell ST (2014) Permaculture for agroecology: design, movement, practice, and worldview. A review. Agron Sustain Dev 34(2):251-274. https://doi.org/10.1007/s13593-013-0181-6

Gatersleben B (2019) Measuring environmental behaviour. In: Steg L, de Groot JIM (eds) Environ psychology: an introduction (BPS textbooks in psychology). Wiley, Hoboken, pp 155-166 
Geng J, Long R, Chen H, Li W (2017) Exploring the motivation-behavior gap in urban residents' green travel behavior: a theoretical and empirical study. Resources Conserv Recycl 125:282-292. https:// doi.org/10.1016/j.resconrec.2017.06.025

Gifford R, Nilsson A (2014) Personal and social factors that influence pro-environmental concern and behaviour: a review. Int J Psychol [Journal international de psychologie] 49(3):141-157. https://doi. org/10.1002/ijop.12034

Gneezy U, Meier S, Rey-Biel P (2011) When and why incentives (don't) work to modify behavior. J Econom Perspect 25(4):191-210. https://doi.org/10.1257/jep.25.4.191

Grønhøj A, Thøgersen J (2017) Why young people do things for the environment: the role of parenting for adolescents' motivation to engage in pro-environmental behaviour. J Environ Psychol 54:11-19. https://doi.org/10.1016/j.jenvp.2017.09.005

Gutierrez Karp D (1996) Values and their effect on pro-environmental behavior. Environ Behav 28(1):111-133

Heindl P, Kanschik P (2016) Ecological sufficiency, individual liberties, and distributive justice: Implications for policy making. Ecol Econom 126:42-50. https://doi.org/10.1016/j.ecolecon.2016.03.019

Holmgren D (2016) Permakultur. Gestaltungsprinzipien für zukunftsfähige Lebensweisen. Drachen Verlag, Klein Jasedow

Howes M, Wortley L, Potts R, Dedekorkut-Howes A, Serrao-Neumann S, Davidson J et al (2017) Environmental sustainability: a case of policy implementation failure? Sustainability $9(2): 165$. https:// doi.org/10.3390/su9020165

Karp DG (1996) Values and their effect on pro-environmental behavior. Environ Behav 28(1):111-133. https://doi.org/10.1177/0013916596281006

Kennedy E, Beckley T, McFarlane B, Nadeau S (2009) Why we don't "walk the talk" understanding the environmental values/behaviour gap in Canada. Hum Ecol Rev 16(2):151-160

Kollmuss A, Agyeman J (2002) Mind the gap: Why do people act environmentally and what are the barriers to pro-environmental behavior? Environ Educ Res 8(3):239-260. https://doi.org/10.1080/13504 620220145401

kommune-niederkaufungen.de (2019) Willkommen auf der Seite der Kommune Niederkaufungen - Kommune Niederkaufungen. https://www.kommune-niederkaufungen.de/ (accessed 5 Sep 2019)

Puig La, de Bellacasa M (2010) Ethical doings in naturescultures. Ethics Place Environ 13(2):151-169. https://doi.org/10.1080/13668791003778834

Lalot F, Falomir-Pichastor JM, Quiamzade A (2018) Compensation and consistency effects in proenvironmental behaviour: the moderating role of majority and minority support for proenvironmental values. Group Process Intergroup Relat 21(3):403-421. https://doi.org/10.1177/1368430217733117

Lalot F, Quiamzade A, Falomir-Pichastor JM, Gollwitzer PM (2019) When does self-identity predict intention to act green? A self-completion account relying on past behaviour and majority-minority support for pro-environmental values. J Environ Psychol 61:79-92. https://doi.org/10.1016/j.jenvp .2019 .01 .002

Lamnek S (2010) Qualitative Sozialforschung. Lehrbuch; [Online-Materialien (Grundlagen Psychologie, 5 , überarb). Beltz, Weinheim

Loorbach D, Frantzeskaki N, Avelino F (2017) Sustainability transitions research: transforming science and practice for societal change. Annu Rev Environ Resources 42(1):599-626. https://doi. org/10.1146/annurev-environ-102014-021340

Luederitz C, Abson DJ, Audet R, Lang DJ (2017) Many pathways toward sustainability: not conflict but co-learning between transition narratives. Sustain Sci 12(3):393-407. https://doi.org/10.1007/s1162 5-016-0414-0

Mayring P (2010) Qualitative Inhaltsanalyse. Grundlagen und Techniken (Neuausgabe). s.l.: Beltz Verlagsgruppe

McManus B (2010) An integral framework for permaculture. J Sustain Dev. https://doi.org/10.5539/jsd. v3n3p162

Montano DE, Kasprzyk D (2008) Theory of reasoned action, theory of planned behavior, and the integrated behavioral Model. In: Glanz K, Rimer BK, Viswanath K (eds) Health behavior and health education. Theory, research, and practice, 4th edn. Jossey-Bass, San Francisco, pp 67-96

Park S-J, Choi S, Kim E-J (2012) The relationships between socio-demographic variables and concerns about environmental sustainability. Corp Soc Responsib Environ Manage 19(6):343-354. https:// doi.org/10.1002/csr.284

Patel J, Modi A, Paul J (2017) Pro-environmental behavior and socio-demographic factors in an emerging market. Asian J Business Ethics 6 (2):189-214. https://doi.org/10.1007/s13520-016-0071-5 
permaculture.co.uk (2019) The permaculture principles. https://www.permaculture.co.uk/sites/default/ files/images/permacultureprinciples.jpg (accessed 5 Sep 2019)

Rhodes CJ (2012) Feeding and healing the world: through regenerative agriculture and permaculture. Sci Progress 95(4):345-446. https://doi.org/10.3184/003685012X13504990668392

Rosenthal G (2018) Interpretive social research. An introduction. Göttingen University Press; Universitätsverlag Göttingen, Göttingen

Roux-Rosier A, Azambuja R, Islam G (2018) Alternative visions: permaculture as imaginaries of the Anthropocene. Organization 25(4):550-572. https://doi.org/10.1177/1350508418778647

Sheeran P, Webb TL (2016) The intention-behavior gap. Soc Pers Psychol Compass 10(9):503-518. https ://doi.org/10.1111/spc3.12265

Steg L, Vlek C (2009) Encouraging pro-environmental behaviour: an integrative review and research agenda. J Environ sPsychol 29(3):309-317. https://doi.org/10.1016/j.jenvp.2008.10.004

Steg L, Bolderdijk JW, Keizer K, Perlaviciute G (2014) An integrated framework for encouraging pro-environmental behaviour: the role of values, situational factors and goals. J Environ Psychol 38:104-115. https://doi.org/10.1016/j.jenvp.2014.01.002

Tabernero C, Hernández B (2011) Self-s. Environ Behav 43(5):658-675. https://doi.org/10.1177/00139 16510379759

Thompson CW, Aspinall P, Montarzino A (2008) The childhood factor. Environ Behav 40(1):111-143. https://doi.org/10.1177/0013916507300119

United Nations (2019) SDGs: sustainable development knowledge platform. https://sustainabledevelopme nt.un.org/sdgs (accessed 5 Sep 2019)

van der Werff E, Steg L, Keizer K (2013) It is a moral issue: the relationship between environmental selfidentity, obligation-based intrinsic motivation and pro-environmental behaviour. Global Environ Change 23(5):1258-1265. https://doi.org/10.1016/j.gloenvcha.2013.07.018

van der Werff E, Steg L, Keizer K (2014) I am what i am, by looking past the present. Environ Behav 46(5):626-657. https://doi.org/10.1177/0013916512475209

Vitari C, David C (2017) Sustainable management models: innovating through permaculture. J Manage Dev 36(1):14-36. https://doi.org/10.1108/JMD-10-2014-0121

Webb TL, Sheeran P (2006) Does changing behavioral intentions engender behavior change? A meta-analysis of the experimental evidence. Psychol Bull 132(2):249-268. https://doi. org/10.1037/0033-2909.132.2.249

Whitmarsh L, O’Neill S (2010) Green identity, green living? The role of pro-environmental self-identity in determining consistency across diverse pro-environmental behaviours. J Environ Psychol 30(3):305-314. https://doi.org/10.1016/j.jenvp.2010.01.003

Wittmayer JM, Schäpke N, van Steenbergen F, Omann I (2014) Making sense of sustainability transitions locally: how action research contributes to addressing societal challenges. Crit Policy Stud 8(4):465-485. https://doi.org/10.1080/19460171.2014.957336 